\title{
Splenic vein enlargement, a rare cause of nutcracker syndrome
}

\author{
Mehdi Karami ${ }^{1}$, hossein kouhi ${ }^{2}$, Seyedeh Fatemeh Sadatmadani ${ }^{1}$, Bahar Sadeghi ${ }^{1}$, Zeynab \\ Rostamiyan $^{1}$, and Mozhdeh Hashemzadeh ${ }^{1}$ \\ ${ }^{1}$ Isfahan University of Medical Sciences \\ ${ }^{2}$ Affiliation not available
}

May 29, 2020

\begin{abstract}
Nutcracker syndrome refers to symptomatic compression of left renal vein. There are many reasons for that. We report a case that the enlargement of splenic vein has caused to nutcracker syndrome. Results implies that not firm venous structures can be cause of nutcracker syndrome.
\end{abstract}

\section{Key clinical message}

Abnormal enlargement of the splenic vein is one of the etiologies of Natcracker syndrome that should be considered when examining the causes of this syndrome. Because knowing rare etiologies can help correctly diagnose Natcracker syndrome and reduce its mortality.

\section{Introduction}

Nutcracker syndrome (NCS) is the symptomatic clinical condition in which of left renal vein (LRV) becomes compressed usually between abdominal aorta and superior mesenteric artery (SMA). NCS is important because secondary chronic LRV hypertension may lead to chronic renal disease or renal vein thrombosis (1). The most common cause of NCS is the short distance between SMA and abdominal aorta (1-4). Other reported causes are retroperitoneal pathologies as tumors or lymphadenopathies. Venous causes are very rare but splenic vein enlargement has not been reported. $(1,3,5)$. NCS can happen at any age from childhood to seventh decade (6-11) with peaking spread in middle age adults $(10,11)$. In this case, NCS is secondary to compression effect of enlarged splenic vein on LRV.

\section{Case history}

A $55 \mathrm{y} / \mathrm{o}$ woman, known case of hairy cell leukemia complained from intermittent abdominal pain (mainly in left flank), nausea, weight loss and loss of appetite from 3 months ago. The patient's family history was unremarkable and has undergone chemotherapy treatment from four months ago. Physical examination positive findings were huge splenomegaly \& cachexia. Her height was 140 centimeter and her weight was 35 kilograms $(B M I=17.85)$. Vital signs were normal. Laboratory positive finding was: $\mathrm{HB}=8.1 \mathrm{~g} / \mathrm{dl}$. Urine analysis was normal.

In abdominal ultrasound, Heterogeneity and increase in splenic parenchymal echogenicity, huge splenomegaly as spleen span of $210 \mathrm{~mm}$ was detected.

Computerized tomography scan (CT scan) confirmed huge splenomegaly and heterogeneity of splenic parenchymal density that indicated splenic infarction. Splenic vein was markedly enlarged in diameter of $19 \mathrm{~mm}$ which had compression effect on LRV. Marked prominency of both gonadal veins and congestion of pelvic veins bilaterally was detected which represents that left gonadal vein and bilateral pelvic veins are 
drainaged via right gonadal vein and this is secondary to LRV compression. These findings lead us that NCS had been occurred.

CT scan showed the normal angle and distance between the Abdominal Aorta and SMA. No retroperitoneal pathology was shown. Both kidneys were normal. Mild ascites, Mild hepatomegaly and evidence of secondary portal hypertension were also noticed. The patient was referred to surgery department for splenectomy to reveal her symptoms.

\section{Discussion}

NCS should be considered in differential diagnosis of patients with intermittent flank pain. According to this case, abnormally enlarged venous structures such as splenic vein which don't have a firm consistency can be mentioned as unusual causes of NCS.

The causes of NCS are divided to three main groups:

1. Arterial causes: the most common cause of NCS is proximity of SMA to abdominal aorta (1-4). Also other arterial causes are abdominal aortic aneurysm, overarching testicular artery and ectopic ventral right renal artery

2. Retroperitoneal tumors or pathologies such as pancreatic neoplasm, chronic pancreatitis, para-aortic lymphadenopathy and decreased retro-peritoneal mesenteric fat tissue

3. Venous causes (that are very rare): LRV duplication, left renal ptosis, Left-sided IVC, hemi-azygos continuation and persistent left superior vena cava combination (as high pressure veins) $(1,3,5)$. Splenic vein enlargement has not been reported as a cause of NCS and this is the first time that an enlarged organic vein is reported as a cause of NCS.

All of the mechanisms involved in LRV compression lead to LRV outflow obstruction (1).

In our case SMA syndrome was one of the differential diagnoses due to rapid weight loss and nausea but imaging data ruled it out (12). CT scan findings showed huge splenomegaly, splenic infarction, and enlarged splenic vein with compression effect on LRV (NCS) (Figure 1). Secondary prominency of both gonadal veins and pelvic congestion were also noticed that represented drainage of these veins through right gonadal vein in the setting of compression of LRV in NCS (Figure 2). The interesting and unique point of our case is a compression effect on LRV that has been made by an enlarged venous structure (enlarged splenic vein) without having a firm or muscular consistency, instead of the arteries or other solid pathologies. In a similar case report, the massively dilated common bile duct which hasn't a firm structure was reported as an unusual etiology for NCS (13). The most common symptoms and signs of NCS are abdominal pain, left flank pain and hematuria (14).

As the another interesting point, abdominal and left flank pain existed in our case while hematuria as a main clinical manifestation of NCS wasn't obtained (15).

NCS is an important diagnosis due to the significant morbidity associated with it, including the risk of chronic renal disease from long-term LRV hypertension and thrombosis (1).

Knowing about the rare etiologies can help in accurate diagnosis of NCS, which will lead to a reduction of its morbidity. To our knowledge, abnormal enlargement of a venous structure has not been reported as an etiology for NCS.

Declaration of patient consent: The authors certify that they have obtained appropriate patient consent forms.

Financial support and sponsorship

Nil.

Acknowledgment: 
Research Team Appreciates clinical informationsist research center dependent on Deputy of research and technology of Isfahan University of Medical Sciences

\section{Authorship}

Author 1: Mehdi Karami: Responsible for monitoring the accuracy of medical content

Author 2: Hossein Kouhi: Responsible for manuscript preparation, editing, review and its guarantee

Email: Hkoohi91@gmail.com

Author 3: Seyedeh Fatemeh Sadatmadani: Responsible for literature search, data acquisition and help in manuscript preparation

Author 4: Bahar Sadeghi: Responsible for literature search, data acquisition and help in manuscript preparation

Author 5: Narges Rostamiyan: Responsible for literature search, data acquisition and help in manuscript preparation

Author 6: Mozhdeh Hashemzadeh: Responsible for reviewing content in terms of writing principles and help in literature search

\section{References}

1. Said SM, Gloviczki P, Kalra M, Oderich GS, Duncan AA, D Fleming M, et al. 2013. Renal nutcracker syndrome: surgical options. Semin Vasc Surg; 26:35-42.

2. Scultetus AH, Villavicencio JL, Gillespie DL.2001. The nutcracker syndrome: its role in the pelvic venous disorders. J Vasc Surg; 34:812-9.

3. Mahmood SK, Oliveira GR, Rosovsky RP. An easily missed diagnosis: flank pain and nutcracker syndrome. BMJ Case Rep 2013. http://dx.doi.org/10.1136/bcr-2013-009447.

4. Shin JI, Park JM, Lee JS, Kim MJ. 2007. Effect of renal Doppler ultrasound on the detection of nutcracker syndrome in children with hematuria. Eur J Pediatr; 166:399-404.

5. Okada M, Tsuzuki K, Ito S. 1998. Diagnosis of the nutcracker phenomenon using two-dimensional ultrasonography. Clin Nephrol; 49:35-40.

6. Shin Jl, Lee JS, Kim MJ. 2006. The prevalence, physical characteristics and diagnosis of nutcracker syndrome. Eur J Vasc Endovasc Surg; 32:335-6.

7. Venkatachalam S, Bumpus K, Kapadia SR, Gray B, Lyden S, Shishehbor MH. 2011. The nutcracker syndrome. Ann Vasc Surg; 25:1154-64.

8. Buschi AJ, Harrison RB, Norman A, Brenbridge AG, Williamson BR, Gentry RR, et al. 1980. Distended left renal vein: CT/sonographic normal variant. AJR Am J Roentgenol; 135:339-42.

9. Ahmed K, Sampath R, Khan MS. 2006. Current trends in the diagnosis and management of renal nutcracker syndrome: a review. Eur J Vasc Endovasc Surg; 31:410-6.

10. He Y, Wu Z, Chen S, Tian L, Li D, Li M, et al. 2014.Nutcracker syndrome-how well do we know it? Urology; 83:12-7.

11. Kurklinsky AK, Rooke TW. 2010. Nutcracker phenomenon and nutcracker syndrome. Mayo Clin Proc; 85:552-9.

12. Ananthan K, Onida S, Davies AH. 2017. Nutcracker Syndrome: An Update on Current Diagnostic Criteria and Management Guidelines. Eur J Vasc Endovasc Surg; 53(6):886-94. 
13. Orczyk K, Wysiadecki G, Majos A, Stefańczyk L, Topol M, Polguj M. 2017. What Each Clinical Anatomist Has to Know about Left Renal Vein Entrapment Syndrome (Nutcracker Syndrome): A Review of the Most Important Findings. Biomed Res Int; 2017:1-7.

14. Mina E, El Sadr AR. 1974. Proceedings: Anatomical and surgical aspects in the operative management of varicocele. West Afr J Pharmacol Drug Res; 2 (1):100-101.

15. Dołowy J, Stoinska A, Kuśmierska M, Kuniej T, Plucińska I, Jaźwiec P. 2011. A case of a spontaneous splenorenal shunt associated with the nutcracker syndrome. Polish J Radiol ; 76(4):49-51.

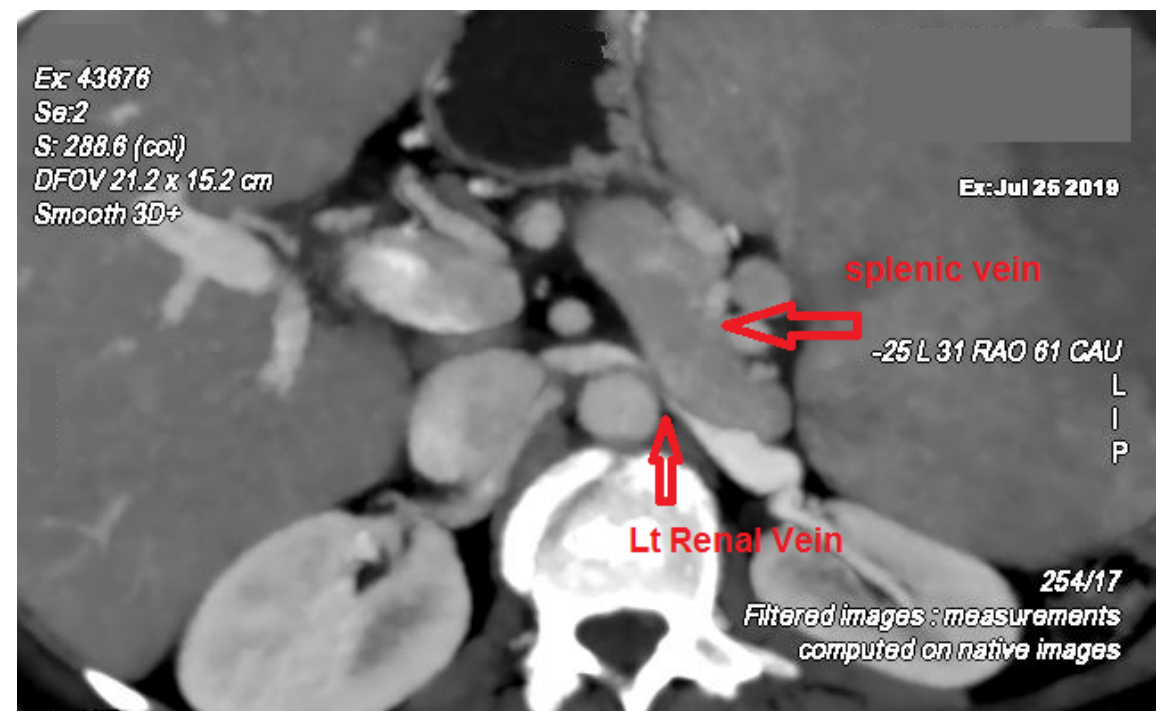




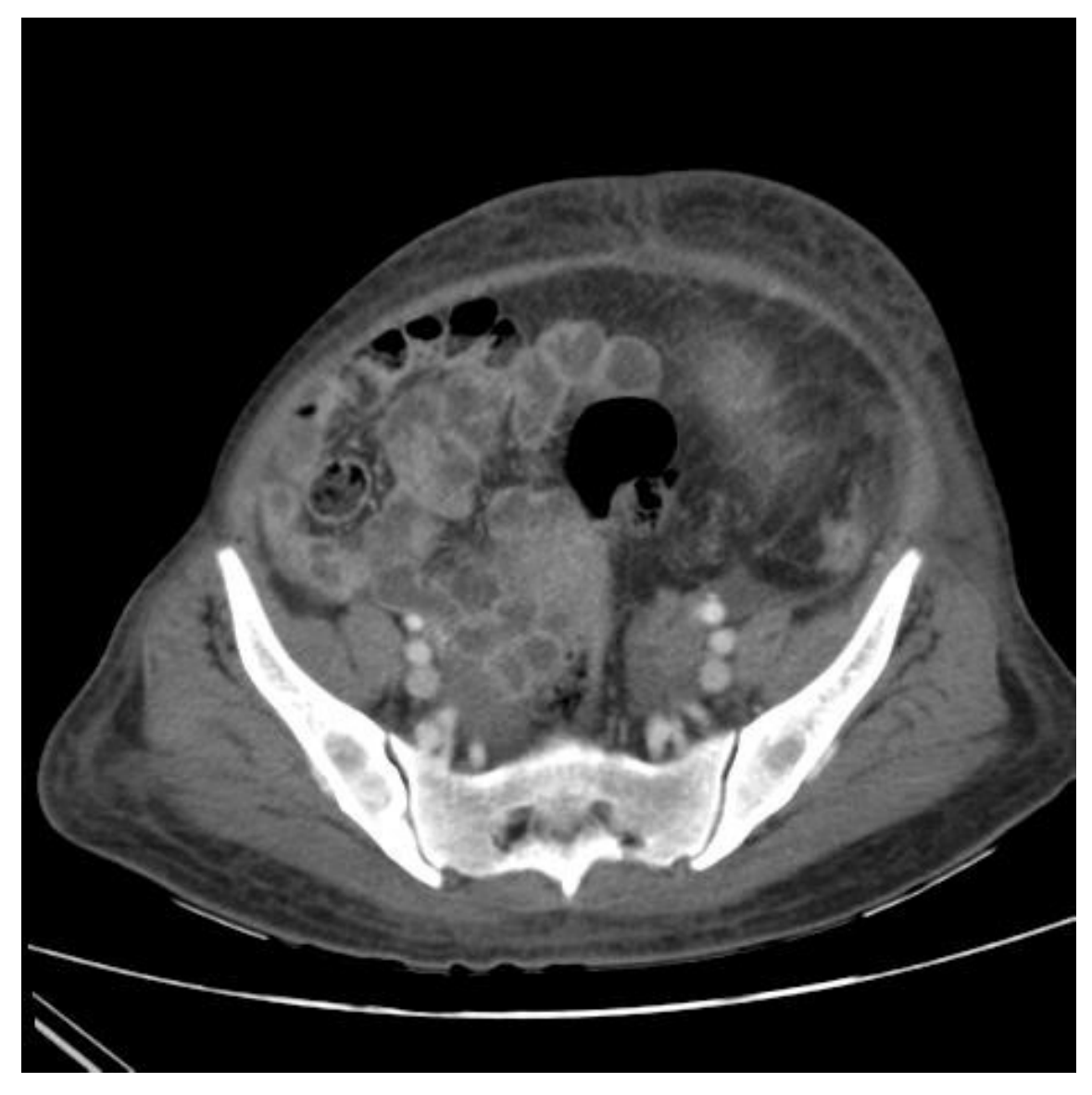

